\title{
Molecular Characterization of a Powdery Mildew Resistance Gene in Wheat Cultivar Suwon 92
}

\author{
X.-Y. Xu, G.-H. Bai, B. F. Carver, G. E. Shaner, and R. M. Hunger
}

\begin{abstract}
First and third authors: Department of Plant and Soil Sciences, Oklahoma State University, Stillwater 74078; second author: U.S. Department of Agriculture-Agricultural Research Service-Plant Science and Entomology Research Unit, 4008 Throckmorton Hall, Manhattan, KS 66506; fourth author: Department of Botany and Plant Pathology, Purdue University, West Lafayette, IN 47907; and fifth author: Department of Entomology and Plant Pathology, Oklahoma State University, Stillwater 74078.
\end{abstract}

Accepted for publication 4 January 2006.

\begin{abstract}
Xu, X.-Y., Bai, G.-H., Carver, B. F., Shaner, G. E., and Hunger, R. M. 2006. Molecular characterization of a powdery mildew resistance gene in wheat cultivar Suwon 92. Phytopathology 96:496-500.

Powdery mildew, caused by Blumeria graminis f. sp. tritici, is an important foliar disease of wheat worldwide. Pyramiding race-specific genes into a single cultivar and combining race-specific resistance genes with durable resistance genes are the preferred strategies to improve the durability of powdery mildew resistance. The objectives of this study were to characterize a powdery mildew resistance gene in Suwon 92 and identify gene-specific or tightly linked molecular markers for markerassisted selection (MAS). A population of recombinant inbred lines (RILs) was derived by single seed descent from a cross between Suwon 92 and a susceptible cultivar, CI 13227. The RILs were screened for adult-plant infection type of powdery mildew and characterized with amplified fragment length polymorphism (AFLP) and simple sequence
\end{abstract}

ABSTRACT repeat (SSR) markers. The linked markers explained 41.3 to $69.2 \%$ of the phenotypic variances measured in 2 years. A morphological marker, hairy glume, was also associated with powdery mildew resistance in Suwon 92, and explained 43 to $51 \%$ of the phenotypic variance. The powdery mildew resistance gene in Suwon 92 was located on the short arm of chromosome $1 \mathrm{~A}$ where $P m 3$ was located. Two gene-specific markers were developed based on the sequence of the cloned $P m 3 b$ gene. These two markers, which were mapped at the same locus in the peak region of the LOD score for the RIL population, explained most of the phenotypic variance for powdery mildew resistance in the RIL population. The powdery mildew resistance in Suwon 92 is most likely conditioned by the Pm3 locus. The gene markers developed herein can be directly used for MAS of some of the Pm3 alleles in breeding programs.

Additional keywords: Triticum aestivum.
Wheat powdery mildew, caused by the obligate biotrophic parasitic fungus Blumeria graminis (DC) E.O. Speer f. sp. tritici, is an important foliar disease of wheat worldwide and is promulgated by the heavy use of high-yielding semidwarf cultivars, irrigation, and nitrogen fertilizer (1). Resistance to powdery mildew typically demonstrates a "boom-and-bust" cycle because the use of single resistance genes results in a shift to virulent pathogen races that quickly spread over long distances with subsequent loss of resistance in a relatively short time period. Methods for breeding durable powdery mildew resistant cultivars include pyramiding race-specific genes, using partial-resistance genes, or combining both types of resistance genes. However, a partial-resistance gene by itself may not always provide satisfactory protection, while the other strategies are time-consuming, labor-intensive, and may be limited by the availability of corresponding races of the pathogen for differentiation of race-specific resistance genes.

Molecular mapping may provide a simple procedure to characterize and identify genes for powdery mildew resistance and improve the durability of powdery mildew resistance. Successful marker-assisted pyramiding of the genes for powdery mildew resistance stimulated the identification of molecular markers (11). Molecular markers have been identified with linkage to $P m 1$, Pm2, Pm3, Pm4, Pm5, Pm6, Pm8, Pm12, Pm13, Pm17, Pm18, $P m 21, P m 24, P m 25, P m 26, P m 27$, and $P m 30$ (4,5,9). Quantitative

Corresponding author: G.-H. Bai; E-mail address: gbai@ksu.edu

DOI: 10.1094/PHYTO-96-0496

This article is in the public domain and not copyrightable. It may be freely reprinted with customary crediting of the source. The American Phytopathological Society, 2006 trait loci for powdery mildew resistance also have been characterized $(6,10)$. However, most of the markers identified are restriction fragment length polymorphism markers that require complicated techniques and relatively high cost for sample analysis, and some are still distant from target genes; thus, they may not be suitable for marker-assisted selection (MAS). Therefore, convenient gene-specific markers for powdery mildew resistance genes are urgently needed for breeding applications.

More recently, $P m 3 b$ has been cloned (19). The cloned Pm3 gene provides essential gene sequence for developing gene-specific markers for $P m 3$ gene that $P m 3$-specific markers are essential for the effective introgression of $P m 3$ alleles into commercial cultivars and for pyramiding $P m 3$ with other $P m$ genes.

Suwon 92 is a semidwarf Korean wheat cultivar that shows resistance to powdery mildew under field conditions. Hence, our objectives were to elucidate the inheritance of the powdery mildew resistance in Suwon 92 and identify specific markers linked to the powdery mildew resistance gene in Suwon 92 for use in MAS.

\section{MATERIALS AND METHODS}

Plant materials. Suwon 92 is resistant to powdery mildew, has short apical awns and hairy glumes, and matures early. In contrast, CI 13227 from the United States is susceptible to powdery mildew and fully awned, has hairless glumes, and matures late. A cross was made between Suwon 92 and CI 13227, and 101 recombinant inbred lines (RILs) were developed by single-seed descent at Purdue University. Leaf tissue from $\mathrm{F}_{10}$ plants grown in a greenhouse at Oklahoma State University, Stillwater, was used for DNA isolation. 
A pair of near-isogenic lines, Chancellor and Chul $/ 8 \times$ Chancellor, were used to develop powdery mildew resistance-gene markers. Chul, the carrier of $P m 3 b$, was used for successful cloning of Pm3b (19).

Disease evaluation. The 101 RILs and the two parents were evaluated in 1994 and 1995 for powdery mildew reaction under natural infection at the Agronomy Center for Research and Education, Purdue University, West Lafayette, IN. The evaluation was conducted using a randomized block design with two replications for RILs and five replications for parents. Each experimental line was planted in three 1-m rows. Infection type (IT) of powdery mildew on plants in each plot was recorded on a 1-to-6 scale, in which $1=$ highly resistant (no visible disease symptom); $2=$ resistant (showing hypersensitive necrotic flecks); $3=$ moderately resistant (minute colonies with few conidia); 4 = moderately susceptible (colonies with moderately developed hyphae and moderate conidial production); $5=$ susceptible (colonies with well-developed hyphae and abundant conidia, but not coalesced colonies); and $6=$ highly susceptible (colonies with well-developed hyphae, abundant conidia, and coalesced colonies). Glume type was scored as 0 (hairless) or 1 (hairy glumed).

Analysis of amplified fragment length polymorphism markers. Genomic DNA was isolated from 2-week-old wheat seedlings by the CTAB (cetyltrimethylammonium) method (14). A method using fluorescence-labeled primers was adapted to generate amplified fragment length polymorphism (AFLP) markers with a Li-Cor IR-4200 DNA Analyzer (Li-Cor Inc., Lincoln, NE) (18). In brief, about $300 \mathrm{ng}$ of wheat genomic DNA was double-digested with Pst I and MseI restriction enzymes. Pst primers were labeled with infrared fluorescence dyes. A bulked segregant analysis (BSA) (13) method was employed to screen informative AFLP primers. Equal amounts of DNA from five highly resistant RILs were pooled to construct the resistant bulk, while equal amounts of DNA from five highly susceptible RILs were mixed to construct the susceptible bulk. Based on previous screening results, 17 Pst I and 36 MseI primers with three to four selective nucleotides were chosen for screening (Table 1). Informative primers detecting polymorphism both between the two parents and between the two bulks were used to genotype the population.

AFLP bands were separated in a $6.5 \%$ denaturing polyacrylamide gel running in the Li-Cor DNA Analyzer. Electrophoresis conditions were set at $1,500 \mathrm{~V}, 40 \mathrm{~W}, 35 \mathrm{~mA}$, and $50^{\circ} \mathrm{C}$ for $3 \mathrm{~h}$ in $1 \times$ Tris-borate-EDTA (TBE) buffer. Gels were prepared as described in the user's manual from the manufacturer. A 68-well comb was used for lane formation and $0.8 \mu$ of each sample was loaded into separated wells. Segregation patterns were manually inspected on a computer screen.

Analysis of simple sequence repeat markers. In an initial linkage analysis, seven AFLP markers associated with a resistance gene in Suwon 92 were identified. To detect simple sequence repeat (SSR) markers linked to this gene, a revised BSA method was applied. Two bulks were reconstructed differing in the presence or absence of seven AFLP markers that closely associated with powdery mildew resistance. The resistant bulk contained equal amounts of DNA from each of five highly resistant RILs with the Suwon 92 allele at all seven AFLP loci, and the susceptible bulk contained equal amounts of DNA from each of five highly susceptible RILs with the CI 13227 allele at all seven AFLP loci. Three resistant lines in the resistant bulk and four susceptible lines in the susceptible bulk were the same as those used in the initial BSA screening of AFLP primers. The selected RILs between the two bulks also showed highly divergent responses to powdery mildew in 1994 and 1995 field experiments. The two bulks, together with DNA from the two parents, were used to screen SSR primers.

A tailed polymerase chain reaction (PCR) primer was used for SSR analysis by adding a 19-base M13 oligo sequence (M13 tail) to the 5' end of each forward SSR primer. Thus, each SSR reaction used three primers: two unlabeled SSR primers with one having an attached M13 sequence tail, and one infrared fluorescence dye-labeled M13 primer with the same sequence as the tail sequence attached to one of the SSR primers. For each $10-\mu \mathrm{l} \mathrm{SSR}$ reaction, $50 \mathrm{ng}$ of genomic DNA was added to a PCR mixture containing $2 \mathrm{mM}$ dNTP, $1 \times$ PCR buffer, $2.5 \mathrm{mM} \mathrm{MgCl}_{2}, 0.6$ units of Taq polymerase, 0.5 pmol SSR primers, and 1 pmol M13 primer. PCR was performed using a touchdown program initiated at $95^{\circ} \mathrm{C}$ for $5 \mathrm{~min}$ followed by five cycles of $95^{\circ} \mathrm{C}$ for $45 \mathrm{~s}, 68^{\circ} \mathrm{C}$ for $5 \mathrm{~min}$, and $72^{\circ} \mathrm{C}$ for $1 \mathrm{~min}$, with a reduction in annealing temperature $\left(68^{\circ} \mathrm{C}\right)$ of $2^{\circ} \mathrm{C}$ per cycle; another five cycles of $95^{\circ} \mathrm{C}$ for $45 \mathrm{~s}, 58^{\circ} \mathrm{C}$ for $2 \mathrm{~min}$, and $72^{\circ} \mathrm{C}$ for $1 \mathrm{~min}$ with a reduction in annealing temperature $\left(58^{\circ} \mathrm{C}\right)$ of $2^{\circ} \mathrm{C}$ per cycle; and then an additional 25 cycles of $95^{\circ} \mathrm{C}$ for $45 \mathrm{~s}, 50^{\circ} \mathrm{C}$ for $2 \mathrm{~min}$, and $72^{\circ} \mathrm{C}$ for $1 \mathrm{~min}$. A 5-min final extension step at $72^{\circ} \mathrm{C}$ occurred before soaking the PCR product at $4^{\circ} \mathrm{C}$. After PCR amplification, $5 \mu \mathrm{l}$ of formamide stopping buffer was added before the samples were denatured at $95^{\circ} \mathrm{C}$ for $5 \mathrm{~min}$. The denatured PCR products were separated in a $6.5 \%$ denaturing polyacrylamide gel in the Li-Cor IR-4200 DNA Analyzer (Li-Cor Inc.) and manually scored as previously described for AFLP.

Development of powdery mildew resistance gene markers. The $P m 3 b$ sequence was retrieved from GenBank (accession no. AY325736). The sequence of the coding region was used to design primers with Primer 3 software. As described in SSR analysis above, a 19-base M13 tail was attached to the 5' end of each forward primer and an additional infrared fluorescence dyelabeled M13 primer was used for PCR detection. The primers were synthesized by Integrated DNA Technologies, Inc. (Coralville, IA) and initially screened for polymorphisms between the two near-isogenic lines (Chancellor and Chul/ $8 \times$ Chancellor), two parents, and two bulks. For a $10-\mu \mathrm{l}$ PCR reaction, $50 \mathrm{ng}$ of genomic DNA was added to a PCR mixture containing $2 \mathrm{mM}$ dNTP, $1 \times$ PCR buffer, $2.5 \mathrm{mM} \mathrm{MgCl}_{2}, 0.9$ units of Taq polymerase, $0.5 \mathrm{pmol}$ each of sequence tagged site (STS) primers, 1 pmol M13 primer, $0.5 \mu \mathrm{l}$ of $10 \%$ PVP, and $0.5 \times$ BSA. The PCR cycles consisted of an initial step of $94^{\circ} \mathrm{C}$ for $5 \mathrm{~min}$ followed by 36 cycles of $30 \mathrm{~s}$ at $94^{\circ} \mathrm{C}, 30 \mathrm{~s}$ at $48^{\circ} \mathrm{C}$, and $40 \mathrm{~s}$ at $72^{\circ} \mathrm{C}$ with a final step of $7 \mathrm{~min}$ at $72^{\circ} \mathrm{C}$. The PCR products were denatured and separated in a $6.5 \%$ denaturing polyacrylamide gel in the LiCor IR-4200 DNA Analyzer as described for SSR.

Data analysis. A one-way analysis of variance (ANOVA) was used to identify markers that were significantly associated with powdery mildew resistance $(P<0.05)$. Genetic linkage maps were constructed using MAPMAKER 3.0 (8) and a LOD threshold was set at 4.0. Centimorgan values were calculated based on the Kosambi mapping function (7). Since the IT scale is semiquantitative and interval mapping with such data is satisfactorily robust to map plant resistance genes $(16,17)$, single-marker analysis and interval analysis were performed using QGENE software (15) to

TABLE 1. Primer combinations for pre-amplification and selective amplification of amplified fragment length polymorphism analysis ${ }^{\mathrm{a}}$

Pre-amplification primers

Pst $\mathrm{I}$ : GACTGCGTACATGCAG

MseI: GATGAGTCCTGAGTAA

Selective amplification primers

PstI: $p$ ACT, $p$ ACTG, $p$ AGT, $p$ CAT, $p$ CATG, $p$ CTC, $p$ TGC, $p$ AGC, $p$ CGA, $p \mathrm{ACG}, p \mathrm{ACA}, p \mathrm{AGG}, p \mathrm{CAG}, p \mathrm{CGT}, p \mathrm{CTCG}, p \mathrm{GCTG}, p \mathrm{GTG}$

Mse I: $m$ ACGC, $m$ AGC, $m \mathrm{CAA}, m \mathrm{CAC}, m \mathrm{CACG}, m \mathrm{CAG}, m \mathrm{CAGT}, m \mathrm{CAT}$, $m \mathrm{CGAC}, m \mathrm{CTA}, m \mathrm{CTC}, m \mathrm{CTG}, m \mathrm{CTGA}, m \mathrm{CTT}, m \mathrm{GAC}, m \mathrm{GCG}$, $m$ TGC, $m$ GCAG,$m$ GTG, $m$ ATGC, $m$ ACAG, $m$ ACGT, $m$ AGAC, $m$ AGCT, $m$ AGGC, $m$ AGTG, $m$ CACG, $m$ CGCT, $m$ CGAT, $m$ CGTA, $m$ CTCG, $m$ TGCG, $m$ TCGA, $m$ GGCT, $m$ GCAT, $m$ CGA

a " $p$ " and " $m$ " represent the pre-amplification primer sequences of PstI and MseI, respectively. 
characterize the effects of each marker and to detect the location of the resistance gene in Suwon 92. The SAS procedure, GCHART, was used to create phenotypic distribution histograms (SAS Institute, Cary, NC).

\section{RESULTS}

Powdery mildew resistance in RILs. Reactions of the RILs to natural infection by the powdery mildew fungus were consistent between 1994 and 1995. In each year, the two parents contrasted significantly in powdery mildew resistance $(P<0.05)$, with scores of "1" (1994) and "2" (1995) for Suwon 92, and "5" for CI 13227 in both years. Although the 101 RILs showed continuous variation for IT, most RILs had a reaction similar to one of the parents (Fig. 1). The IT of individual RILs ranged from 1 to 6 in 1994 and 2 to 5 in 1995 with a mean IT of 3.3 and 3.5 in 1994 and 1995, respectively. Transgressive segregation was observed for susceptibility, but not for resistance (Fig. 1). The correlation coefficient for ITs among RILs between the 2 years was highly significant $(r=0.89 ; P<0.0001)$.

Considering ITs from 1 to 3 as resistant and 4 to 6 as susceptible, the ratio of resistant to susceptible RILs did not deviate from a 1:1 ratio in either year $\left(\chi^{2}=0.346, P>0.5\right.$ in $1994 ; \chi^{2}=$ $0.154, P>0.5$ in 1995), suggesting that this classification is consistent with a single-gene model. Glume type score was also consistent between years.

Mapping the powdery mildew resistance gene in Suwon 92. A total of 612 pairs of AFLP (PstI/MseI) primers were screened using BSA (Table 1). Informative primers that detected at least one polymorphic band between the two parents and the two initial
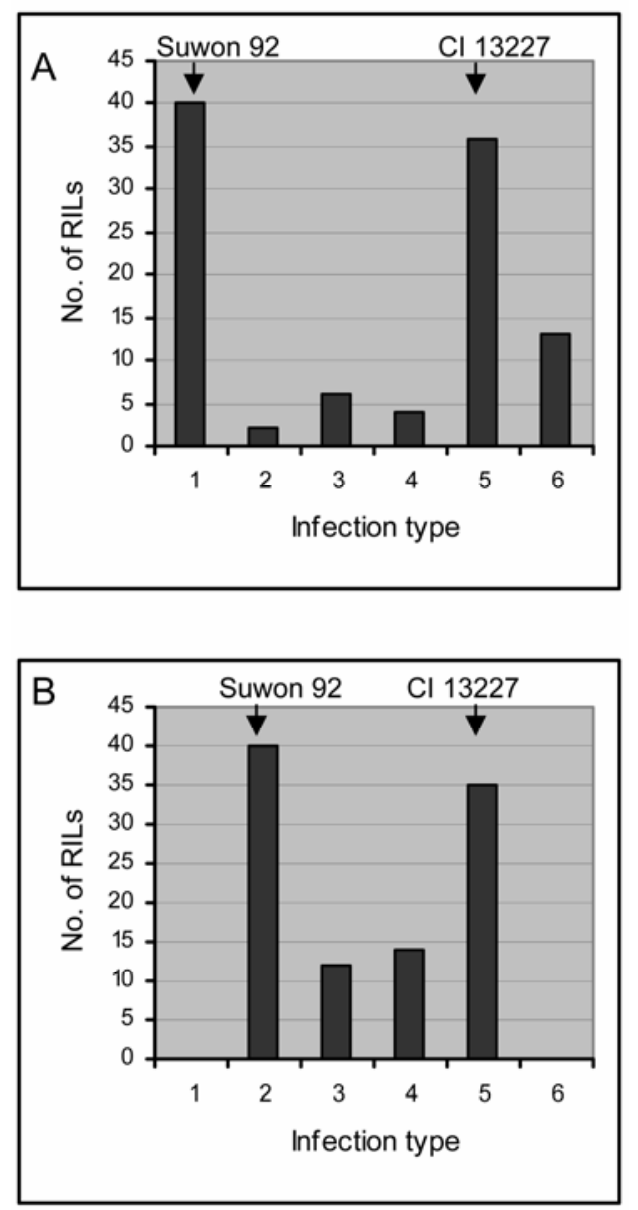

Fig. 1. Frequency distributions for powdery mildew infection type measured in A, 1994 and B, 1995 for 101 recombinant inbred lines (RILs) derived from CI $13227 \times$ Suwon 92 and their parents. bulks were used to screen the 101 RILs. One-way ANOVA identified seven AFLP markers that were closely associated with powdery mildew resistance, and these markers were grouped into one linkage group in the initial linkage analysis.

Preliminary analysis indicated that hairy glume was correlated with powdery mildew resistance in the RIL population. Given that the $H g$ gene encoding hairy glume was previously mapped on chromosome 1AS (12), a set of SSR markers previously mapped on chromosome $1 \mathrm{AS}$ was used to screen the parents and the modified bulks constructed from the informative AFLP markers. Among these SSR markers, XPSP2999 was polymorphic between the bulks. The sizes of the polymorphic bands were $158 \mathrm{bp}$ in the resistant bulk and Suwon 92, and 166 bp in the susceptible bulk and CI 13227 (Fig. 2).

Seven AFLPs, one SSR, and one morphological marker (hairy glume) were mapped in the same linkage group spanning 20.3 centimorgans. All nine markers showed highly significant associations with powdery mildew resistance in both 1994 and 1995 field experiments. The determination coefficients $\left(R^{2}\right)$ of these markers ranged from 51 to $69 \%$ in 1994 , and 41 to $57 \%$ in

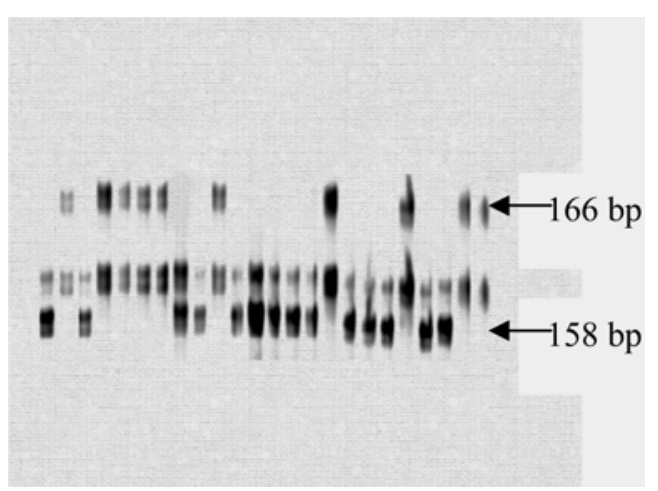

Fig. 2. An simple sequence repeat (SSR) image generated from the Li-Cor DNA Analyzer (Li-Cor Inc., Lincoln, NE) showing the cosegregation pattern of an SSR marker (XPSP2999) with powdery mildew resistance in the population of recombinant inbred lines (RILs) derived from CI $13227 \times$ Suwon 92. Lane identities from left to right are Suwon 92, CI 13227, and RILs 1 to 22 .

TABLE 2. Determination coefficients $\left(R^{2}\right)$ and allelic additive effects of amplified fragment length polymorphism, simple sequence repeat, sequence tagged site, and morphological markers associated with powdery mildew infection type (IT) measured in 2 years $^{\mathrm{a}}$

\begin{tabular}{|c|c|c|c|c|c|c|}
\hline \multirow[b]{2}{*}{ Marker } & \multirow[b]{2}{*}{ Year } & \multirow[b]{2}{*}{$R^{2 \%}$} & \multirow[b]{2}{*}{ LOD } & \multicolumn{2}{|c|}{ Allele mean (IT) (1-6) } & \multirow{2}{*}{$\begin{array}{c}\text { Additive } \\
\text { effect }\end{array}$} \\
\hline & & & & CI 13227 & Suwon 92 & \\
\hline \multirow[t]{2}{*}{$X p m 3 b-1 / X P m 3 b-2$} & 1994 & 77 & 31.9 & 5.0 & 1.6 & 1.7 \\
\hline & 1995 & 59 & 19.1 & 4.5 & 2.5 & 1.0 \\
\hline \multirow[t]{2}{*}{ XPSP2999 } & 1994 & 69 & 25.2 & 4.8 & 1.6 & 1.6 \\
\hline & 1995 & 57 & 18.4 & 4.5 & 2.5 & 1.0 \\
\hline \multirow[t]{2}{*}{ XCAG.ATGC193 } & 1994 & 69 & 25.5 & 4.9 & 1.6 & 1.6 \\
\hline & 1995 & 59 & 18.4 & 4.6 & 2.6 & 1.0 \\
\hline \multirow[t]{2}{*}{ ХCGT.ACAG145 } & 1994 & 64 & 21.4 & 4.8 & 1.7 & 1.6 \\
\hline & 1995 & 55 & 16.8 & 4.5 & 2.6 & 0.9 \\
\hline \multirow[t]{2}{*}{ XCGT.GCAG145 } & 1994 & 64 & 21.4 & 4.8 & 1.7 & 1.6 \\
\hline & 1995 & 51 & 14.3 & 4.5 & 2.7 & 0.9 \\
\hline \multirow{2}{*}{ ХCGA.CTA 125} & 1994 & 57 & 18.3 & 4.7 & 1.7 & 1.5 \\
\hline & 1995 & 50 & 14.8 & 4.4 & 2.6 & 0.9 \\
\hline \multirow[t]{2}{*}{ XCAT.AGAC180 } & 1994 & 57 & 18.3 & 4.7 & 1.7 & 1.5 \\
\hline & 1995 & 48 & 13.9 & 4.4 & 2.6 & 0.9 \\
\hline \multirow[t]{2}{*}{ Hairy glume } & 1994 & 51 & 15.2 & 4.5 & 1.7 & 1.4 \\
\hline & 1995 & 43 & 12.2 & 4.3 & 2.6 & 0.8 \\
\hline \multirow[t]{2}{*}{ XCAG.GTG65 } & 1994 & 53 & 16.5 & 4.5 & 1.7 & 1.4 \\
\hline & 1995 & 43 & 12.1 & 4.3 & 2.6 & 0.8 \\
\hline \multirow[t]{2}{*}{ XCAG.AGAC96 } & 1994 & 51 & 14.5 & 4.5 & 1.7 & 1.4 \\
\hline & 1995 & 41 & 10.8 & 4.3 & 2.6 & 0.8 \\
\hline
\end{tabular}

a All additive effects are $P<0.0001$. 
1995 (Table 2). The effects of single marker-allele substitution on IT values varied from 1.4 to 1.6 in 1994 and 0.8 to 1.0 in 1995 .

Initial interval mapping consistently indicated that the powdery mildew resistance gene in Suwon 92 was close to SSR marker XPSP2999. Since XPSP2999 was previously mapped on chromosome 1A (3) and the hairy glume $(H g)$ gene was previously mapped on chromosome 1AS (12), the gene in Suwon 92 was tentatively assigned to chromosome $1 \mathrm{AS}$.

Pm3-specific markers. Among the known powdery mildew resistance genes, only $P m 3$ was identified on chromosome 1 AS (12). A total of 10 alleles ( $P m 3 a$ to $P m 3 j$ ) have been reported at this locus. To determine if the resistance gene in Suwon 92 resides at the same locus as $P m 3,10$ primer pairs, designed based on the cloned $P m 3 b$ sequence, were screened using the two parents, the two AFLP-based modified bulks, and a pair of nearisogenic lines. Two of them, Pm3b-1 (forward, 5'-TGCCTAGAAGATCTATGCTTATCAG; and reverse, 5'-CATGCCAGCACAGTTCAG) and Pm3b-2 (forward, 5'-TGTTCAGTTGTGGTACATCCT; and reverse, 5'-GACTGTACCAACCTATAACCTC), amplified a band in the resistant bulk, resistant parent (Suwon 92), and the $P m 3 b$ near-isogenic line (Chul/ $8 \times$ Chancellor), but not in the susceptible bulk, susceptible parent (CI 13227), and susceptible recurrent parent (Chancellor). Hence, the two markers are specific markers for Pm3 locus, and Suwon 92 carries a $P m 3$ allele. Both markers are dominant. Xpm $3 b-1$ and Xpm3b-2 amplified a 364- and 314-bp band, respectively, from Suwon 92, Chul/8 $\times$ Chancellor, and resistant bulk (Fig. 3). These two markers were mapped at the same locus on the peak region of the LOD score in the RIL population (Fig. 4) and explained 77 and $59 \%$ of the phenotypic variance in 1994 and 1995, respectively. This indicates that the resistance in Suwon 92 is conditioned by an allele of $P m 3$.

\section{DISCUSSION}

Among the known powdery mildew resistance genes, $P m 3$ has the most alleles and is one of the three powdery mildew resistance genes (Pm3, Pm17, and Mld) that alone confers a high level of resistance to the French powdery mildew populations (2). Eight of the $P m 3$ alleles (Pm3a to $P m 3 h$ ) have been used in breeding programs, and the two newly identified alleles ( $P m 3 i$ and $P m 3 j$ ) are effective against all existing European powdery mildew populations (20). Our study shows that Suwon 92 carries a resistance gene at Pm3 locus. This gene is either one of the known Pm3 alleles or a new allele. Allelism tests may provide further information on its allelic relationship with other known Pm alleles.

More recently, $P m 3 b$ has been cloned (19). The conserved sequence of the $P m 3$ gene may facilitate the rapid isolation of other $P m 3$ alleles. This in turn may reveal the mechanisms that are involved in the evolution of the $P m 3$ gene family and facilitate understanding of the mechanisms by which specificity of disease resistance is determined in wheat. Meanwhile, the successful cloning of $P m 3 b$ offers an opportunity to develop Pm3-specific markers. Here, we reported the first $P m 3$-specific markers,
$X p m 3 b-1$ and $X p m 3 b-2$, for powdery mildew resistance using the cloned $P m 3 b$ sequence. These markers should be useful for Pm3targeted selection given that the sequences are highly conserved among different alleles at the same locus. For example, apart from Pm3b, Xpm3b-1 and Xpm3b-2 can also be used to tag Pm3a, $P m 3 c$, and $P m 3 f$ (X.-Y. Xu, unpublished data). Further use of the Pm3-specific markers may accelerate the introduction of Pm3 alleles into high yield, good quality wheat cultivars. Pm3-specific gene markers $X p m 3 b-1$ and $X p m 3 b-2$ are effective markers that can be directly used in marker-assisted breeding programs to improve selection efficiency. For example, in 1994 and 1995, 94 and $82 \%$ of the RILs with Suwon 92 allele at the Xpm3b$1 / X p m 3 b-2$ locus had a $P m$ IT value less than or equal to 3 , respectively; and 98 and $92 \%$ of the RILs with the CI 13227 allele had a $P m$ IT value greater than 3, respectively. Since the phenotypic data were collected under natural infection conditions in the field, and the pathogen population might not be a single race and fungal races might vary from year to year, the powdery mildew resistance data and Xpm3b-1/Xpm3b-2 marker data did not show perfect agreement. Further phenotyping of the RIL population under controlled conditions may provide more accurate information.

The linked SSR marker XPSP2999 may play a complementary role to the Pm3-specific markers. Since Xpm3b-1 and Xpm3b-2 were designed based on the $P m 3 b$ sequence, they may not be used in MAS for all Pm3 alleles. In that event, XPSP2999 may be a good surrogate for $X p m 3 b-1$ and $X p m 3 b-2$. For example, $X P S P 2999$ may be used to tag Pm3e since Xpm3b-1 and Xpm $3 b-2$

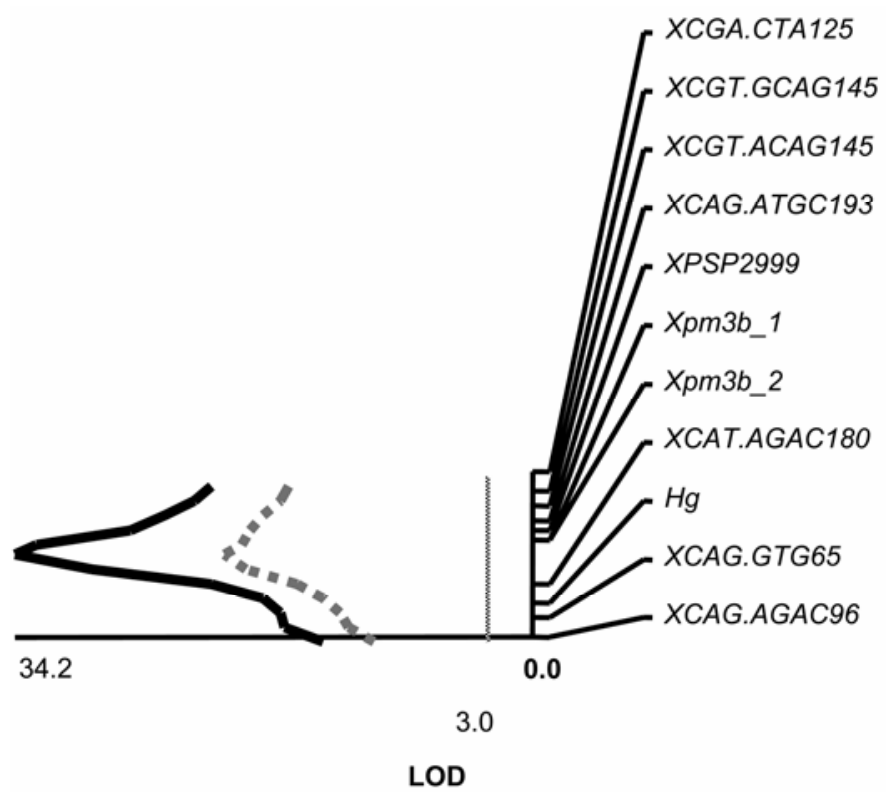

Fig. 4. The likelihood plots for the location of a powdery mildew resistance gene from Suwon 92 on wheat chromosome 1AS determined from disease data in 1994 (solid line) and 1995 (dotted line). The vertical line represents LOD value of 3.0 .

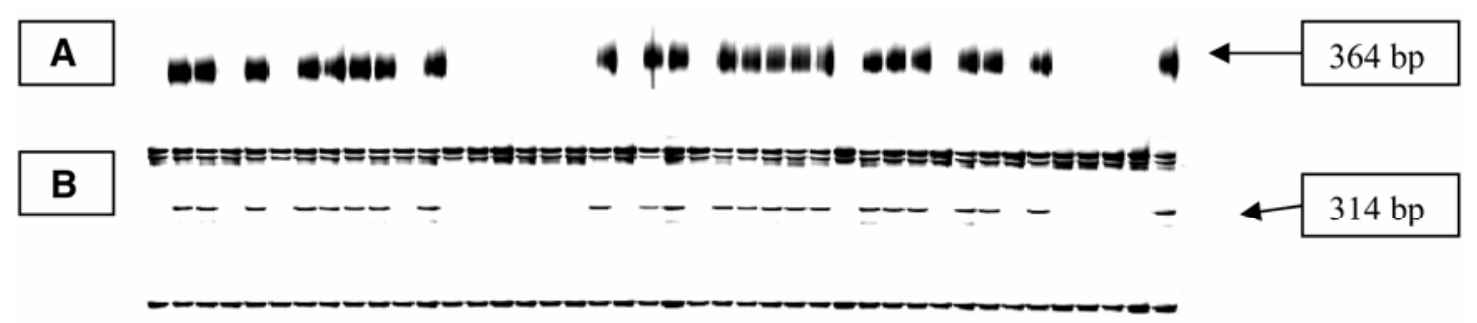

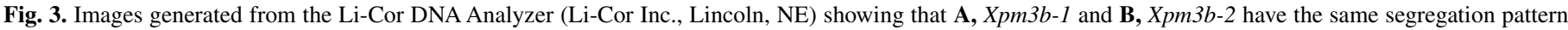

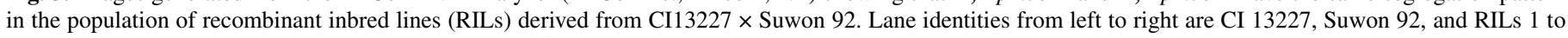
40. No band was amplified from CI 13227 (first lane of $\mathbf{A}$ ) for Xpm3b-1. 
cannot amplify the target bands from W176, a cultivar known to carry a $P m 3 e$ gene.

From this study, AFLP markers XCAG.ATGC193, XCGT.ACAG145, and XCGT.GCAG145 were consistently and significantly associated with powdery mildew resistance across the 2 years. However, the application of these markers in breeding programs depends on successful conversion of them into STS markers due to their technical complexity and the high cost of sample preparation and marker detection.

The hairy glume trait explained 51 and $43 \%$ of the total variance for IT in 1994 and 1995, respectively (Table 2). In 1994, 39 of 46 RILs $(85 \%)$ with hairy glume were scored as moderately resistant, resistant, or highly resistant (IT $\leq 3$ ), whereas 48 of 55 RILs $(87 \%)$ with hairless glume were scored as moderately susceptible, susceptible, or very susceptible (IT > 3). In 1995, similar results were observed: $72 \%$ of the RILs with hairy glume were scored as either moderately resistant or resistant, while $84 \%$ of the RILs with hairless glume were scored as moderately susceptible or susceptible. Differences in mean IT score between lines with hairy glume and those without hairy glume were highly significant (Table 2), indicating that glume types may serve as an indirect selection criterion for Suwon 92-conferred resistance. Since the hairy glume trait can be monitored in the field, it may be a suitable marker for breeders to use during initial screening.

\section{ACKNOWLEDGMENTS}

We thank D. Marshall (USDA-ARS, Plant Science Research Unit, North Carolina State University, Raleigh, NC) for providing isogenic lines of powdery mildew resistance genes. A portion of this research was funded by the Oklahoma Wheat Research Foundation and by the Oklahoma Agricultural Experiment Station. Mention of trade names or commercial products in this article is solely for the purpose of providing specific information and does not imply recommendation or endorsement by the U.S. Department of Agriculture.

\section{LITERATURE CITED}

1. Bennett, A. G. A. 1984. Resistance to powdery mildew in wheat: A review of its use in culture and breeding programs. Plant Pathol. 33:279-300.

2. Bougot, Y., Lemoin, M., Pavoine, M. T., Barloy, D., and Doussinault, G. 2002. Identification of a microsatellite marker associated with Pm3 resistance alleles to powdery mildew in wheat. Plant Breed. 121:325-329.

3. Devos, K. M., Bryan, G. J., Collins, A. J., Stephenson, P., and Gale, M. D. 1995. Application of two microsatellite sequences in wheat storage proteins as molecular markers. Theor. Appl. Genet. 90:247-252.
4. Gupta, P. K., Varshney, R. K., Sharma, P. C., and Ramesh, B. 1999. Molecular markers and their applications in wheat breeding. Plant Breed. 118:369-390.

5. Huang, X.-Q., and Roder, M. 2004. Molecular mapping of powdery mildew resistance genes in wheat: A review. Euphytica 137:203-223.

6. Keller, M., Keller, B., Schachermayr, G., Winzeler, M., Schmid, J. E., Stamp, P., and Messer, M. M. 1999. Quantitative trait loci for resistance to powdery mildew in a segregating wheat $\times$ spelt population. Theor. Appl. Genet. 98:903-912.

7. Kosambi, D. D. 1944. The estimation of map distances from recombination values. Ann. Eugen. 12:172-175.

8. Lander, E. S., Green, P., Abrahamson, J., Barlow, A., Daly, M. J., Lincoln, S. E., and Newburg, I. 1987. Mapmaker: An interactive computer package for constructing primary genetic linkage maps of experimental and natural populations. Genomics 1:174-181.

9. Langridge, P., Lagudah, E. S., Holton, T. A., Appels, R., Sharp, P. J., and Chalmers, K. J. 2001. Trends in genetic and genome analysis in wheat: A review. Aust. J. Agric. Res. 52:1043-1077.

10. Liu, S., Griffey, C. A., and Saghai Maroof, M. A. 2001. Identification of molecular markers associated with adult plant resistance to powdery mildew in common wheat cultivar Massey. Crop Sci. 41:12681275.

11. Liu, J., Liu, D., Tao, W., Li, W., Wang, S., Chen, P., Cheng, S., and Gao, D. 2000. Molecular marker-facilitated pyramiding of different genes for powdery mildew resistance in wheat. Plant Breed. 119:21-24.

12. McIntosh, R. A., and Bennett, F. G. A. 1978. Telocentric mapping of genes $\mathrm{Pm} 3 \mathrm{a}$ and $\mathrm{Hg}$ on chromosome $1 \mathrm{~A}$ of hexaploid wheat. Cer. Res. Comm. 6:9-14.

13. Michelmore, R. W., Paran, I., and Kesseli, R. V. 1991. Identification of markers linked to disease-resistance genes by bulked segregant analysis: A rapid method to detect markers in specific genomic regions by using segregating populations. Proc. Natl. Acad. Sci. 88: 9828-9832.

14. Murray, M. G., and Thompson, W. F. 1980. The isolation of high molecular weight plant DNA. Nucleic Acids Res. 8:4321-4325.

15. Nelson, J. C. 1997. Qgene: Software for marker-based genomic analysis and breeding. Mol. Breed. 3:239-245.

16. Rebai, A. 1997. Comparison of methods for regression interval mapping in QTL analysis with non-normal traits. Genet. Res. 69:69-74.

17. Singh, R. P., Nelson, J. C., and Sorrells, M. E. 2000. Mapping Yr28 and other genes for resistance to stripe rust in wheat. Crop Sci. 40:11481155.

18. Xu, X.-Y., Bai, G.-H., Carver, B. F., Shaner, G. E., and Hunger, R. H. 2005. Mapping of QTLs prolonging the latent period of Puccinia triticina infection in wheat. Theor. Appl. Genet. 110:244-251.

19. Yahiaoui, N., Srichumpa, P., Dudler, R., and Keller, B. 2004. Genome analysis at different ploidy levels allows cloning of the powdery mildew resistance gene Pm3b from hexaploid wheat. Plant J. 37:528-538.

20. Zeller, F. J., and Hsam, S. L. K. 1998. Progress in breeding for resistance to powdery mildew in common wheat (Triticum aestivum L.). Pages 178181 in: Proc. 9th Int. Wheat Genet. Symp., University Extension Press, University of Saskatchewan, Saskatoon, Canada. 